\title{
Actinic keratosis post pterygium surgery
}

\section{Queratosis actínica poscirugía de pterigión}

René Hernán Parada-Vásquez ${ }^{1 *}$, Juan Pablo Medina-López ${ }^{2}$ and Agustín del Valle-Penella ${ }^{3}$

${ }^{1}$ Anterior segment fellowship; ${ }^{2}$ Third year Ophthalmology resident; ${ }^{3}$ First year Ophthalmology resident. Vision Institute, La Carlota Hospital, Montemorelos, Nuevo León, Mexico

A 50-year-old female patient who consulted for presenting discomfort in the left eye. She had a history of pterygium surgery in the left eye eight months ago. Her far visual acuity, without correction in the right eye: 20/20; and in the left eye: $20 / 30$. Physical examination in the left eye revealed normal ductions and versions, without restriction of eye movements, as well as the presence of an elevated lesion with regular borders and a "granuloma" appearance with a diameter of $2 \times 3 \mathrm{~mm}$ in the bulbar conjunctiva (Fig. 1). The cornea and the rest of the anterior segment had a normal aspect. An excisional biopsy was performed. The microscopic study showed stratified, non-keratinized squamous epithelium (Fig. 2A), with areas of acanthosis (Fig. 2B), multiple zones of superficial epithelial proliferation with keratinization (Figs. $2 \mathrm{C}$ and $\mathrm{D}$ ), respecting the basal membrane; the stroma shows changes of elastotic degeneration, without dysplastic changes. The diagnosis of the conjunctival excisional biopsy is an actinic keratosis of the left eye.

\section{Ethical disclosures}

Protection of human and animal subjects. The authors declare that no experiments were performed on humans or animals for this study.

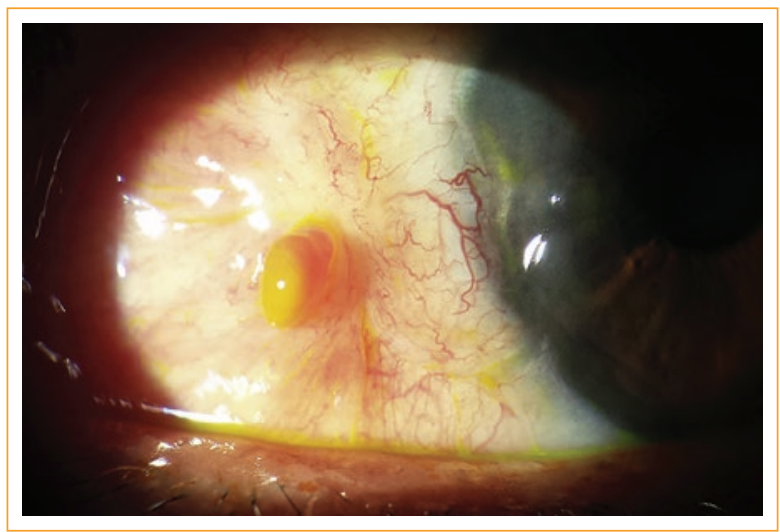

Figure 1. Lesion with granulomatous features in the bulbar conjunctiva after pterygium surgery.

Confidentiality of data. The authors declare that they have followed the protocols of their work center on the publication of patient data.

Right to privacy and informed consent. The authors have obtained the written informed consent of the patients or subjects mentioned in the article. The corresponding author is in possession of this document.

\section{Correspondence:}

*René Hernán Parada-Vásquez

Tabachin 10, Alamos 2 da sección Queretaro Date of reception: 30-07-2016

C.P. 76160, Queretaro, Mexico

E-mail: rene_hernan@hotmail.com

Date of acceptance: 31-08-2016

DOI: 10.24875/RMOE.M18000033
Available online: 17-09-2018 Rev Mex Oftalmol(Eng).2018;92(5):236-237 www.rmo.com.mx 2604-1731/@ 2018 Sociedad Mexicana de Oftalmología. Published by Permanyer México SA de CV. This is an Open Access article under the CC BY-NC-ND license (http://creativecommons.org/licenses/by-nc-nd/4.0/). 


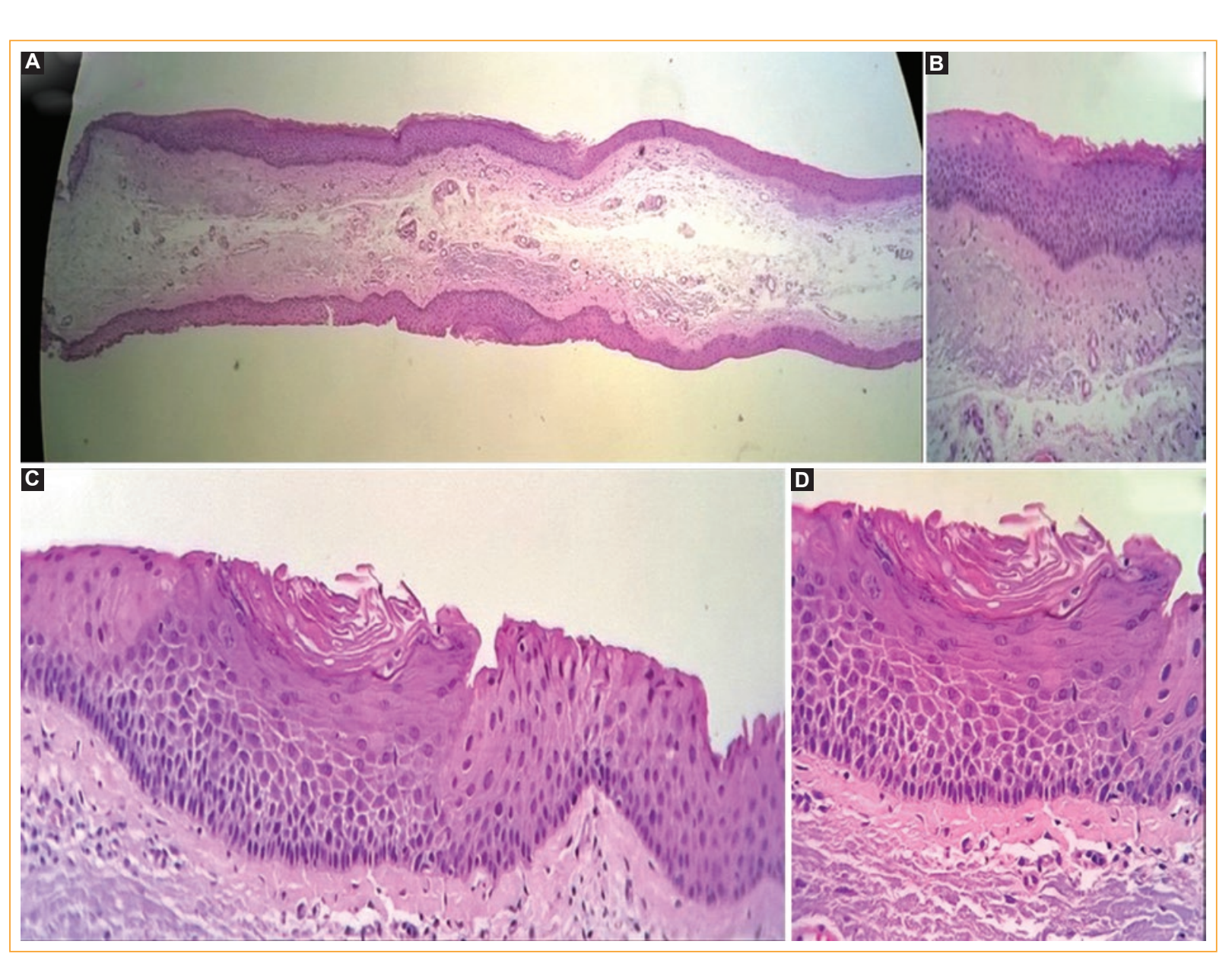

Figure 2. Conjunctival excisional biopsy. A: Stratified simple non-keratinized epithelium, with areas of acanthosis. B: multiple areas of proliferation of superficial epithelium with keratinization (C and $\mathbf{D})$, that respect the basement membrane, with changes of elastotic degeneration in the stroma.

\section{Conflicts of interest}

The authors declare no conflicts of interest.

\section{Funding}

The authors received no specific funding for this work. 